\title{
Disponibilidade de potássio a arroz irrigado por alagamento em solos de várzea ${ }^{1}$
}

\author{
Leandro Souza da Silva ${ }^{2}$, Elisandra Pocojeski ${ }^{3}$, \\ Darinês Britzke 2 , Simone Kaefer ${ }^{4}$, Gustavo Griebeler ${ }^{5}$, Danilo Rhenheimer dos Santos ${ }^{2}$
}

\begin{abstract}
Potassium availability to flooded rice in lowland soils

Non-exchangeable potassium $(\mathrm{K})$ forms are not estimated by usual methods of soil $\mathrm{K}$ availability, like Mehlich-1, but they can contribute to $\mathrm{K}$ nutrition of flooded rice. This study aimed at evaluating $\mathrm{K}$ forms in lowland soils by different chemical methods and associate them to $\mathrm{K}$ absorption by flooded rice. Fourteen lowland soils cultivated with flooded rice (IRGA 417 cultivar) were sampled and used in a greenhouse experiment. The $\mathrm{K}$ forms in the soil samples were extracted before and after rice cultivation by using calcium chlorite, Mehlich-1, sodium tetra phenyl borate (NaTFB) and fluorite acid. The $\mathrm{K}$ uptake was measured in rice shoots. There was a wide variation in $\mathrm{K}$ forms among the lowland soils. The variation in the amount of $\mathrm{K}$ extracted by using the Mehlich-1 method does not explain the $\mathrm{K}$ absorption by irrigated rice plants in every soil. The NaTFB method was more sensitive to evaluate $\mathrm{K}$ availability in lowland soils cultivated with flooded rice plants.
\end{abstract}

KEY-WORDS: Oryza sativa; sodium tetra phenyl borate; potassium absorption.

\section{INTRODUÇÃO}

O arroz é a cultura que responde pelo suprimento de parte das calorias consumidas na alimentação de pessoas em todo o mundo, e os maiores produtores estão situados em países asiáticos, seguidos do Brasil, Estados Unidos e Paquistão.

O Brasil cultivou cerca de 2,4-2,8 milhões de hectares e respondeu pela produção de 11-13 milhões de toneladas nas últimas safras, participando com cerca de $80 \%$ na produção do Mercosul e sendo o maior produtor fora do continente asiático (Sosbai 2014).

\section{RESUMO}

$\mathrm{O}$ método usualmente empregado para avaliação da disponibilidade de potássio (K) no solo (Mehlich-1) não estima as formas não trocáveis do elemento. No entanto, essas formas podem contribuir de maneira significativa no suprimento às plantas de arroz irrigado por alagamento. Objetivou-se avaliar formas de $\mathrm{K}$ em solos de várzea por diferentes métodos e associá-las às quantidades de $\mathrm{K}$ absorvidas por plantas de arroz irrigado por alagamento. O experimento foi conduzido em casade-vegetação, com amostras de 14 solos de várzea cultivados com arroz (cultivar IRGA 417) e irrigados por alagamento. Nas amostras de solo, o K foi extraído com cloreto de cálcio, Mehlich-1, tetrafenil borato de sódio (NaTFB) e ácido fluorídrico, antes e após o cultivo. Na parte aérea das plantas, foi determinada a quantidade de $\mathrm{K}$ absorvido. Houve ampla variação na quantidade de $\mathrm{K}$ total para os solos de várzea. A variação na quantidade de $\mathrm{K}$ extraído pelo método Mehlich-1 não explica a quantidade de K absorvida pelas plantas de arroz irrigado para todos os solos. $\mathrm{O}$ método NaTFB foi mais sensível em estimar o K disponível em solos de várzea cultivados com arroz irrigado por alagamento.

PALAVRAS-CHAVE: Oryza sativa; tetrafenil borato de sódio; absorção de potássio.

O Rio Grande do Sul é o maior Estado produtor de arroz no Brasil, com 8,64 milhões de toneladas obtidas do cultivo de 1,12 milhão de hectares, na safra de 2014/2015, o que representa $44,6 \%$ da área nacional e $67,0 \%$ da produção brasileira (Conab 2015).

O sistema de cultivo tradicionalmente praticado no Rio Grande do Sul é a irrigação por alagamento (mais de $95 \%$ da área cultivada) e, nessas condições, o manejo da adubação segue as Recomendações Técnicas para a Cultura do Arroz Irrigado no Sul do Brasil (Sosbai 2014).

1. Trabalho recebido em mai./2015 e aceito para publicação em nov./2015 (http://dx.doi.org/10.1590/1983-40632015v4535437).

2. Universidade Federal de Santa Maria, Departamento de Solos, Santa Maria, RS, Brasil. E-mails: leandro@smail.ufsm.br, britzke@gmail.com, danilor@smail.ufsm.br.

3. Universidade Tecnológica Federal do Paraná, Dois Vizinhos, PR, Brasil. E-mail: elisandrap@utfpr.edu.br.

4. Empresa de Assistência Técnica e Extensão Rural (Emater), Porto Velho, RO, Brasil.E-mail: sikaeffer@hotmail.com. 5. Ministério da Agricultura, Pecuária e Abastecimento, Unidade de Vigilância Agropecuária de Fronteira, Santana do Livramento, RS, Brasil. E-mail: gustavogriebeler@hotmail.com. 
Os sistemas de recomendação consideram o teor de potássio (K) disponível no solo estimado pela análise química, sendo essa avaliação realizada, na maioria dos casos, pelo método Mehlich-1. Porém, as análises de correlação entre o teor de K disponível no solo e a produtividade de grãos de arroz irrigado por alagamento nem sempre apresentam coeficientes significativos, ou, quando apresentam, os valores são baixos (Lopes 1989, Machado \& Franco 1995, Scivittaro \& Machado 2004), dificultando o estabelecimento do teor crítico das classes de disponibilidade e das doses de fertilizantes potássicos a serem adicionadas.

As recomendações para a cultura (Sosbai 2014) dividem a interpretação da análise de K, para fins de recomendação de adubação, de acordo com três faixas de $\mathrm{CTC}_{\mathrm{pH} 7}(<5 ; 5-15 ;>15)$, sendo os teores críticos de $\mathrm{K}$ de $45 \mathrm{cmol}_{\mathrm{c}} \mathrm{dm}^{-3}, 60 \mathrm{cmol}_{\mathrm{c}} \mathrm{dm}^{-3}$ e $90 \mathrm{cmol}_{\mathrm{c}} \mathrm{dm}^{-3}$, respectivamente, para cada faixa de CTC. Já para a interpretação da análise foliar, são considerados adequados os teores entre $9 \mathrm{~g}$ e $14 \mathrm{~g}$ de $\mathrm{K}$ por $\mathrm{kg}$ de matéria seca, determinados na folha bandeira, no início do florescimento.

A ausência de correlação entre o teor de $\mathrm{K}$ disponível no solo e a produtividade de grãos da cultura tem sido atribuída a fatores como a entrada de $\mathrm{K}$ nas lavouras pela água de irrigação (Vahl 2004, Diel et al. 2007), liberação de K dos minerais (não trocável ou estrutural) (Castilhos et al. 1999, 2002) e sua difusão aumentada (Machado 1985), sendo que essas outras fontes e a ciclagem desse nutriente (Werle et al. 2008) não costumam constar nos resultados da análise do solo, mas interferem na disponibilidade às plantas (Nachtigall \& Vahl 1991b, Ferreira 2003, Scivittaro \& Machado 2004).

Didaticamente, o K do solo pode ser dividido em quatro formas ou compartimentos (Sparks 1987): K na solução do solo; K adsorvido eletrostaticamente nas cargas negativas do solo ou $\mathrm{K}$ trocável; $\mathrm{K}$ adsorvido nas entrecamadas de argilominerais tipo 2:1 e considerado "não trocável"; e K que faz parte da estrutura de minerais, sendo considerado $\mathrm{K}$ estrutural. A forma estrutural está presente nos minerais primários, predominantes nas frações grosseiras do solo, e é liberado lentamente, tendo-se em vista que é dependente do grau de intemperismo químico do mineral (Sharpley 1989). Da mesma forma, o K não trocável está retido com alta energia nas entrecamadas e também não é considerado disponível a curto prazo. Já o K que se encontra adsorvido eletrosta- ticamente na superfície dos minerais é considerado "trocável" (forma em equilíbrio químico rápido com a solução do solo) e prontamente biodisponível (Tisdale et al. 1993). Por isso, essa forma "trocável" é usada como índice de disponibilidade em fertilidade do solo.

Apesar das divisões conceituais, as formas de $\mathrm{K}$ do solo estão em equilíbrio dinâmico umas com as outras (Jalali 2006, Moody \& Bell 2006), de tal forma que, quando ocorre extração de K na solução do solo pelas plantas, sua concentração tende a ser reposta pela liberação do K trocável (Nachtigall \& Vahl 1991b). Por sua vez, quando a quantidade na solução e nos grupos funcionais superficiais diminui drasticamente, parte do $\mathrm{K}$ não trocável pode difundir-se das entrecamadas dos argilominerais $2: 1$ e também se tornar disponível às plantas, acelerando o intemperismo do mineral. Desse modo, o K não trocável pode ser fonte do nutriente às plantas a curto prazo e, nessas condições, poderia explicar diferenças na resposta das plantas de arroz à adubação, quando o K disponível não é adequadamente estimado pelos métodos de análise química do solo.

A disponibilidade de $\mathrm{K}$ às plantas pode ser avaliada por meio de cultivos sucessivos, medindo-se a quantidade de $\mathrm{K}$ acumulado no tecido vegetal e sua relação com as formas extraídas por diferentes métodos químicos (Nachtigall \& Vahl 1991a). Existem métodos químicos utilizados em laboratório para a estimativa das formas de $\mathrm{K}$ encontradas no solo, sendo, assim, possível estimar a liberação desse nutriente a curto, médio e longo prazo. O cloreto de cálcio $\left(\mathrm{CaCl}_{2}\right)$ 0,005 mol L-1 estima o $\mathrm{K}$ na solução do solo (Moody \& Bell 2006); o acetato de amônio $\left(\mathrm{NH}_{4} \mathrm{OAc}\right) \mathrm{pH} 7$, o Mehlich-1 e a resina de troca catiônica estimam o $\mathrm{K}$ disponível, baseado, principalmente, nas formas trocáveis; o tetrafenil borato de sódio (NaTFB) extrai, além do K na solução e o trocável, o K não trocável, forçando a sua difusão das entrecamadas (Cox et al. 1996); e o ácido fluorídrico (HF) permite a extração do K total do solo.

Objetivou-se avaliar as formas de $\mathrm{K}$, em diferentes tipos de solos de várzea, estimadas por diferentes métodos químicos, e relacioná-las com a disponibilidade a plantas de arroz irrigado por alagamento.

\section{MATERIAL E MÉTODOS}

O experimento foi conduzido em casa-de-vegetação e no Laboratório de Química e Fertilidade 
do Solo da Universidade Federal de Santa Maria, em Santa Maria (RS), entre 2007 e 2008.

Foram utilizadas 14 amostras de solos de várzea, coletadas na camada superficial $(0-20 \mathrm{~cm})$, com ampla faixa de variação de características químicas e físicas, em áreas de lavouras de 12 municípios produtores de arroz irrigado, com a seguinte associação entre os locais de coleta e o Sistema Brasileiro de Classificação de Solos (Embrapa 2013): Camaquã (1 - Gleissolo Melânico), Uruguaiana (2 - Vertissolo Ebânico; 3 - Chernossolo Ebânico), Caçapava do Sul (4 - Planossolo Háplico), Santo Antônio da Patrulha (5 - Planossolo Háplico), Santa Maria (6 - Planossolo Háplico), São Gabriel (7 - Planossolo Háplico), Cachoeirinha (8 - Gleissolo Háplico), Restinga Seca (9 - Planossolo Háplico), Cachoeira do Sul (10-11 - Planossolo Háplico), Santa Vitória do Palmar (12 - Planossolo Háplico), Rosário do Sul (13 - Planossolo Háplico) e Paraíso do Sul (14 - Planossolo Háplico). Na Tabela 1, estão descritos os teores de matéria orgânica, a composição granulométrica das amostras (Ranno et al. 2007) e a composição mineralógica de alguns dos solos (Britzke 2010).

As amostras coletadas foram secas ao ar, moídas e passadas em peneira de $2 \mathrm{~mm}$, sendo uma fração destinada à extração do $\mathrm{K}$, conforme os seguintes métodos: $\mathrm{CaCl}_{2}$ (Moody \& Bell 2006), Mehlich-1 (Tedesco et al. 1995), NaTFB (Cox et al. 1996) adaptado para 1 hora de contato (Moody \& Bell
2006) e HF (Pratt 1973). O teor de K dos extratos foi quantificado em fotômetro de chama.

Posteriormente, amostras de 1,1 kg de solo foram incubadas em vasos, com e sem a aplicação de $82,65 \mathrm{mg} \mathrm{kg}^{-1}$ de $\mathrm{K}\left(\mathrm{KH}_{2} \mathrm{PO}_{4}+\mathrm{KCl}\right)$, conforme descrito por Ranno (2004), com a finalidade de criar diferentes níveis de $\mathrm{K}$ disponível nos solos. Nesse momento, foi aplicado o equivalente a $50 \mathrm{mg} \mathrm{kg}^{-1} \mathrm{de}$ $\mathrm{P}$ e $20 \mathrm{mg} \mathrm{kg}^{-1}$ de $\mathrm{N}$, utilizando-se o $\mathrm{NH}_{4} \mathrm{H}_{2} \mathrm{PO}_{4}$ e o $\mathrm{NH}_{4} \mathrm{Cl}$ como fontes desses nutrientes.

O experimento com 14 tipos de solo, com dois níveis de $\mathrm{K}$ e duas repetições de cada tratamento, totalizando 56 unidades experimentais, foi conduzido em delineamento inteiramente casualizado. As sementes de arroz irrigado (cultivar IRGA 417) foram pré-germinadas, sendo, posteriormente, transplantadas oito plântulas por vaso. Aos cinco dias após o transplante, foi realizado um desbaste, deixando-se seis plântulas por vaso. Adicionou-se água destilada, para a formação de uma lâmina de aproximadamente $5 \mathrm{~cm}$, a qual foi mantida até o término do experimento. Em cada um dos vasos, foram realizados três cortes sucessivos da parte área das plantas, a aproximadamente $2 \mathrm{~cm}$ do solo, aos 30, 60 e 90 dias após o transplante. Próximo à data dos cortes, a lâmina de água foi mantida em aproximadamente $1 \mathrm{~cm}$ de altura, para permitir o corte da parte aérea o mais rente ao solo possível e garantir o rebrote das plantas.

A matéria verde da parte aérea do arroz irrigado, de cada corte, foi seca em estufa a $60{ }^{\circ} \mathrm{C}$, até

Tabela 1. Associação entre os locais de coleta dos solos e a classificação taxonômica, atributos físicos e químicos (extraído de Ranno et al. 2007) e mineralógicos (extraídos de Britzke 2010) dos solos utilizados (Santa Maria, RS, 2015).

\begin{tabular}{|c|c|c|c|c|c|c|c|c|}
\hline \multirow{2}{*}{ Município de coleta } & \multirow{2}{*}{$\begin{array}{l}\text { Classificação } \\
\text { Brasileira }^{1}\end{array}$} & M.O. $^{2}$ & Argila & Silte & Areia & \multicolumn{3}{|c|}{ Mineralogia das frações } \\
\hline & & \multicolumn{4}{|c|}{$\mathrm{g} \mathrm{kg}^{-1}$} & Argila & Silte & Areia \\
\hline Camaquã & 1 - Gleissolo Melânico & 70 & 804 & 152 & 44 & $-{ }^{\text {nd }}$ & - & - \\
\hline Uruguaiana & 2 - Vertissolo Ebânico & 55 & 370 & 374 & 256 & Basalto $^{3}$, Es, Ct, Qz, Fp & Qz & Qz \\
\hline Uruguaiana & 3 - Chernossolo Ebânico & 36 & 330 & 570 & 100 & - & - & - \\
\hline Caçapava do Sul & 4 - Planossolo Háplico & 29 & 320 & 500 & 180 & Es, It, Ct, Qz, Fp & Qz, Alb (Fp), Mi & $\mathrm{Qz}, \mathrm{Sa}, \mathrm{Mi}$ \\
\hline Santo Antônio da Patrulha & 5 - Planossolo Háplico & 23 & 225 & 226 & 548 & Granito $^{3}$ & - & $\mathrm{Qz}^{4}$ \\
\hline Santa Maria & 6 - Planossolo Háplico & 19 & 240 & 379 & 380 & Es, It, Ct & Qz & Qz \\
\hline São Gabriel & 7 - Planossolo Háplico & 26 & 245 & 528 & 227 & - & - & - \\
\hline Cachoeirinha & 8 - Gleissolo Háplico & 22 & 200 & 437 & 363 & Granito $^{3}, \mathrm{Ct}$, VeHE, Fp, Qz & Qz & Qz \\
\hline Restinga Seca & 9 - Planossolo Háplico & 16 & 187 & 301 & 512 & Granito $^{3}, \mathrm{Ve}, \mathrm{Ct}, \mathrm{Qz}, \mathrm{Fp}$ & Qz & Qz \\
\hline Cachoeira do Sul & 10 - Planossolo Háplico & 14 & 175 & 308 & 517 & - & - & - \\
\hline Cachoeira do Sul & 11 - Planossolo Háplico & 10 & 128 & 462 & 409 & - & - & - \\
\hline Santa Vitória do Palmar & 12 - Planossolo Háplico & 19 & 123 & 160 & 711 & Granito $^{3}$, Ve, It, Ct, Fp, Qz & Qz, Mi (Fp) & Qz \\
\hline Rosário do Sul & 13 - Planossolo Háplico & 12 & 83 & 157 & 744 & - & - & - \\
\hline Paraíso do Sul & 14 - Planossolo Háplico & 14 & 88 & 175 & 739 & - & - & - \\
\hline
\end{tabular}

${ }^{1}$ Embrapa (2013); ${ }^{2}$ Matéria orgânica do solo; ${ }^{3}$ Material de origem; nd: não determinado; Ct: caulinita; Ve: vermiculita; VeHE: vermiculita com hidroxi entre camadas; Fp: feldspato; Qz: quartzo; Es: esmectita; It: Ilita; Mi: microclínio; Alb: albita; Sa: sanidina. 
massa constante, e foi determinada a produção de matéria seca. $\mathrm{O}$ teor de $\mathrm{K}$ total da parte aérea, em cada um dos cortes, foi determinado por meio de digestão ácida (Tedesco et al. 1995), quantificando-se o K em fotômetro de chama.

Ao final do cultivo, os solos foram secos ao ar, sendo retirada uma fração de cada unidade experimental para determinação de $\mathrm{K}$ por $\mathrm{CaCl}_{2}$ (Moody \& Bell 2006), Mehlich-1 (Tedesco et al. 1995) e NaTFB (Cox et al. 1996) adaptado para 1 hora de contato (Moody \& Bell 2006). Também foi calculada a variação do $\mathrm{K}$ disponível com o cultivo, estimada pela diferença entre os valores de K extraído por Mehlich-1, antes e após o cultivo de arroz, denominado delta $\mathrm{K}$ disponível (Cox et al. 1996), e que foi correlacionado por meio de correlação simples de Pearson, a 5 \%, com a quantidade de $\mathrm{K}$ absorvido pelas plantas de arroz. Os valores de $\mathrm{K}$ absorvido pelas plantas de arroz irrigado foram correlacionados com os valores de K extraído do solo por diferentes métodos químicos, também utilizando-se correlação simples de Pearson a $5 \%$.

\section{RESULTADOS E DISCUSSÃO}

O K total extraído pelo HF variou de $138,2 \mathrm{mg}$ $\mathrm{kg}^{-1}$ a $6.733,1 \mathrm{mg} \mathrm{kg}^{-1}$ (Tabela 2), demonstrando a ampla variação na quantidade de $\mathrm{K}$ total da camada superficial dos solos de várzea coletados neste experimento.

Castilhos \& Meurer (2002) já haviam demonstrado que alguns solos cultivados com arroz irrigado por alagamento apresentavam altos teores de $\mathrm{K}$ total, com variação de $1.935 \mathrm{mg} \mathrm{kg}^{-1}$ a $5.571 \mathrm{mg} \mathrm{kg}^{-1}$ de $\mathrm{K}$, para quatro solos derivados de sedimentos costeiros, aluviais e de granito do Rio Grande do Sul.

A maior amplitude obtida neste estudo é função da maior diversidade de solos com grande variação granulométrica (Tabela 1) e mineralógica, encontrando-se material de origem de basalto em Uruguaiana; arenitos, siltitos, argilitos e folhelhos em Rosário do Sul, Santa Maria, São Gabriel, Restinga Seca, Paraíso do Sul e Cachoeira do Sul; arenitos, siltitos, argilitos, folhelhos, granito, gnaisse, xisto e outros em Dom Pedrito e Caçapava do Sul; e sedimentos de granito em Santa Vitória do Palmar, Cachoeirinha e Santo Antônio da Patrulha, de acordo com Brasil (1973).

No trabalho de Castilhos et al. (2002), foi identificada a presença de feldspatos e micas, nas frações areia e silte (principal fonte de K nos Planossolos), e predomínio de minerais interestratificados mica-esmectita, esmectita com hidróxido-entrecamadas (EHE) e esmectitas, na fração argila (principal fonte de K no Gleissolo e Chernossolo). Neste trabalho, em alguns dos solos utilizados, foram determinados quais minerais estavam presentes nas frações areia, silte e argila (Tabela 1), sendo que os minerais considerados fontes de K (esmectita, ilita, feldspato, vermiculita com hidroxi entre camadas e vermiculita) foram encontrados em alguns solos, tais como Vertissolo Ebânico (amostra 2); Planossolo Háplico (4, 6, 9 e 12) e Gleissolo Háplico (8). A presença desses minerais

Tabela 2. Teor de potássio no solo, antes do cultivo, extraído por cloreto de cálcio $\left(\mathrm{CaCl}_{2}\right)$, Mehlich-1, tetrafenil borato de sódio (NaTFB) e ácido fluorídrico (HF), em solos de várzea do Rio Grande do Sul (Santa Maria, RS, 2015).

\begin{tabular}{|c|c|c|c|c|c|c|c|c|}
\hline \multirow{2}{*}{ Solos } & \multicolumn{2}{|c|}{$\mathrm{HF}$} & \multicolumn{2}{|c|}{ NaTFB } & \multicolumn{2}{|c|}{ Mehlich-1 } & \multicolumn{2}{|c|}{$\mathrm{CaCl}_{2}$} \\
\hline & $\mathrm{mg} \mathrm{kg}^{-1}$ & $\%$ & $\mathrm{mg} \mathrm{kg}^{-1}$ & $\%$ & $\mathrm{mg} \mathrm{kg}^{-1}$ & $\%$ & $\mathrm{mg} \mathrm{kg}^{-1}$ & $\%$ \\
\hline 5 - Planossolo Háplico & 138,2 & 100 & 57,9 & 42 & 61,5 & 44 & 12,3 & 9 \\
\hline 8 - Gleissolo Háplico & 236,9 & 100 & 34,7 & 15 & 31,7 & 13 & 11,9 & 5 \\
\hline 14 - Planossolo Háplico & 394,9 & 100 & 34,7 & 9 & 35,7 & 9 & 13,9 & 4 \\
\hline 9 - Planossolo Háplico & 406,7 & 100 & 46,3 & 11 & 43,6 & 11 & 13,9 & 3 \\
\hline 3 - Chernossolo Ebânico & 710,8 & 100 & 69,5 & 10 & 55,5 & 8 & 15,1 & 2 \\
\hline 7 - Planossolo Háplico & 888,5 & 100 & 81,1 & 9 & 47,6 & 5 & 11,9 & 1 \\
\hline 2 - Vertissolo Ebânico & 888,5 & 100 & 150,6 & 17 & 101,2 & 11 & 16,6 & 2 \\
\hline 13 - Planossolo Háplico & $1.046,5$ & 100 & 57,9 & 6 & 53,6 & 5 & 34,5 & 3 \\
\hline 10 - Planossolo Háplico & $1.046,5$ & 100 & 57,9 & 6 & 49,6 & 5 & 16,6 & 2 \\
\hline 11 - Planossolo Háplico & $1.184,7$ & 100 & 57,9 & 5 & 47,6 & 4 & 18,6 & 2 \\
\hline 6 - Planossolo Háplico & $1.461,1$ & 100 & 185,3 & 13 & 150,7 & 10 & 71,0 & 5 \\
\hline 12 - Planossolo Háplico & $1.626,9$ & 100 & 69,5 & 4 & 55,5 & 3 & 23,8 & 1 \\
\hline 4 - Planossolo Háplico & $6.101,1$ & 100 & 267,4 & 4 & 77,4 & 1 & 9,9 & $<1$ \\
\hline 1 - Gleissolo Melânico & $6.733,1$ & 100 & 267,4 & 4 & 138,8 & 2 & 24,6 & $<1$ \\
\hline
\end{tabular}

Os valores em percentagem representam o percentual em relação ao total extraído por HF. 
com potencial de liberar $\mathrm{K}$ a médio e longo prazo pode justificar os altos teores de $\mathrm{K}$ total encontrados nesses solos (exceto para o Planossolo Háplico 9 e Gleissolo Háplico 8), bem como eventual ausência de reposta à adição de fertilizantes potássicos utilizados nessas áreas.

Outros solos, tais como o Gleissolo Melânico 1 e os Planossolos Háplicos 7, 10, 11 e 13, que apresentaram elevados teores de K total no solo, possivelmente, também apresentam em sua composição minerais com potencial de liberação desse elemento.

Segundo Meurer \& Castilhos (2001), a velocidade com que o $\mathrm{K}$ é liberado depende do tipo de mineral, tamanho das partículas, grau de intemperização e difusão no solo. Nos solos mais intemperizados, minerais resistentes que contêm $\mathrm{K}$, como a mica dioctaedral (muscovita) e vermiculita com hidroxi-entrecamadas (VHE), podem resistir ao intemperismo (Malavolta 1985, Rebertus et al. 1986) e serem responsáveis pelos baixos teores de $\mathrm{K}$ total normalmente encontrados nas frações areia e silte. Esse fato poderia explicar os teores elevados de K total no Gleissolo Melânico $\left(6.733,1 \mathrm{mg} \mathrm{kg}^{-1}\right)$, já que este possui teor de argila superior a $80 \% \mathrm{em}$ sua composição, ou seja, a contribuição de K, provavelmente, não está relacionada somente às frações silte e areia.

Em pesquisa desenvolvida por Unamba-Oparah (1985), a capacidade de suprimento de K de solos altamente intemperizados da Nigéria foi fortemente relacionada com os teores de areia fina e silte. Segundo Kämpf \& Curi (2003), a reposição natural de $\mathrm{K}$ para a solução do solo depende, principalmente, de alterações dos feldspatos e micas, sendo que os feldspatos ocorrem em maior abundância nas frações areia e silte dos solos, sendo considerado importante reserva a longo prazo (Curi et al. 2005).

$\mathrm{O} \mathrm{K}$ extraído pelo $\mathrm{CaCl}_{2}$, que representa o $\mathrm{K}$ da solução do solo mais aquele adsorvido com baixa energia, e, portanto, facilmente dessorvido (Moody \& Bell 2006), variou de 9,9 $\mathrm{mg} \mathrm{kg}^{-1}$ a $71,0 \mathrm{mg} \mathrm{kg}^{-1} \mathrm{de}$ $\mathrm{K}$, representando entre $<1$ e $9 \%$ do $\mathrm{K}$ total dos solos (Tabela 2). Entretanto, esses valores não foram associados com o K absorvido pelas plantas (Figura 1a). Essa baixa correlação pode estar relacionada com a reatividade dos coloides, ou seja, com os teores de matéria orgânica e de argila desses solos, que podem funcionar como tampão de K. Os solos que possuem alto poder tampão de $\mathrm{K}$ têm capacidade de manter constantes os teores de K na solução do solo, seja por meio de adsorção específica + adsorção não específica, quando se aduba com $\mathrm{K}$, ou por meio de dessorção, que repõe o K na solução do solo, quando
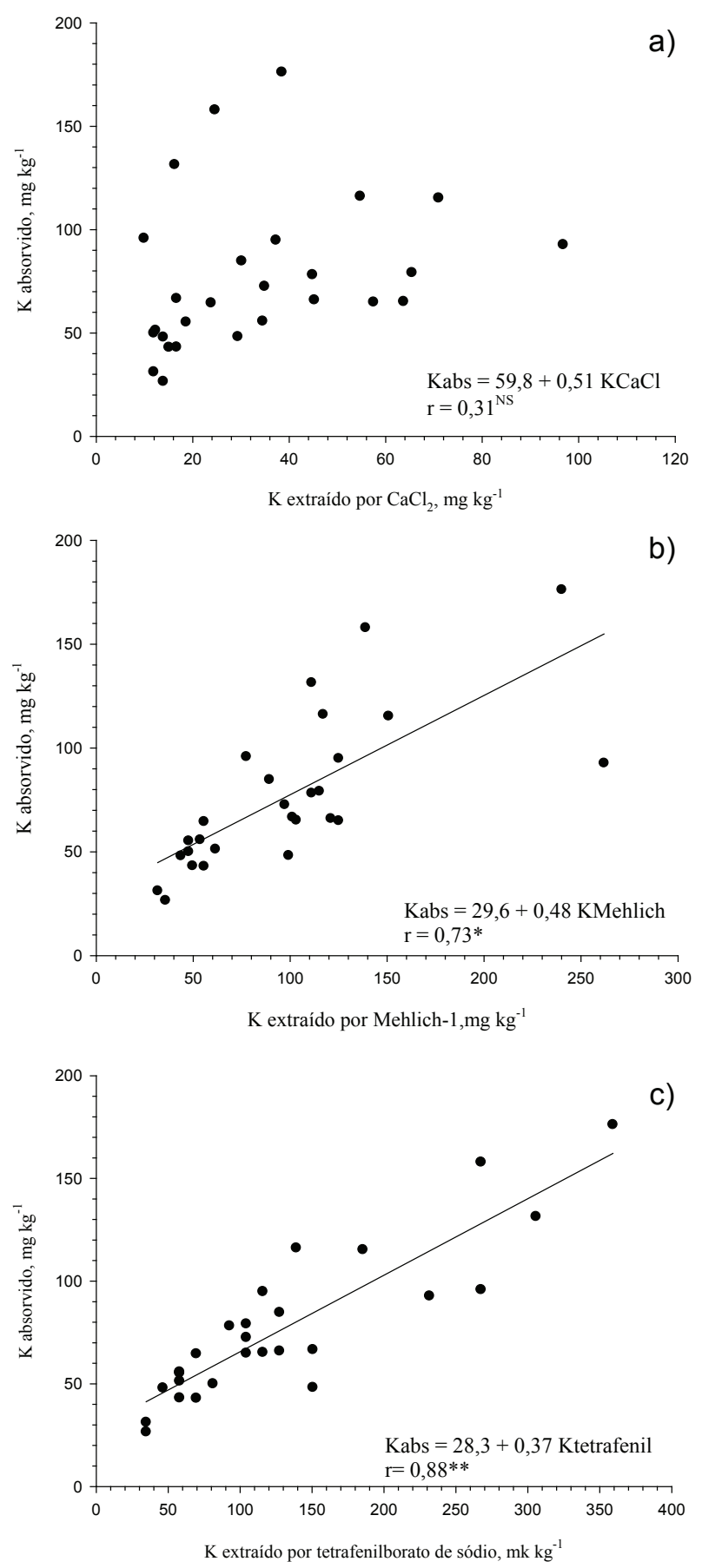

Figura 1. Relação entre o $\mathrm{K}$ absorvido pelas plantas de arroz irrigado e o $\mathrm{K}$ extraído antes do cultivo por $\mathrm{CaCl}_{2}$ (a), Mehlich-1 (b) e tetrafenil borato de sódio (c), para 14 solos de várzea do Rio Grande do Sul (Santa Maria, RS, 2015). ${ }^{\text {ns }}$ não significativo; * significativo a $0,5 \%$; ** significativo a $0,1 \%$. 
esse elemento é perdido do solo por lixiviação ou absorção pela planta (Santos et al. 2013). No entanto, Prezotti \& Defelipo (1987) ressaltam a dificuldade de se comparar o poder tampão de K entre solos, em razão da grande diversidade de metodologias na caracterização do K no solo. Além disso, não há consenso sobre quais valores são considerados altos para o poder tampão de $\mathrm{K}$.

Com base nesses resultados, pode-se inferir que métodos mais brandos de extração, como o $\mathrm{CaCl}_{2}$, não são bons para estimar a disponibilidade de $\mathrm{K}$ às plantas. $\mathrm{O}$ tamponamento do $\mathrm{K}$ da solução do solo (fator capacidade) não é acessado por esse extrator, como pode ser observado, especialmente, nos solos 4 - Planossolo Háplico e 1 - Gleissolo Melânico. Nesses solos, os valores de $\mathrm{K}$ extraído por $\mathrm{CaCl}_{2}$ representaram menos de $1 \%$ do $\mathrm{K}$ total (Tabela 2).

Em relação ao $\mathrm{K}$ extraído por Mehlich-1, considerado o $\mathrm{K}$ disponível às plantas (CQFS RS/ $\mathrm{SC} 2004$ ), as quantidades variaram de $31,7 \mathrm{mg} \mathrm{kg}^{-1}$ a $150,7 \mathrm{mg} \mathrm{kg}^{-1}$ (Tabela 2), correspondendo a diferentes classes de disponibilidade de K (Sosbai 2014). Essa variação pode estar relacionada com as características mineralógicas dos solos (Britzke et al. 2012) e eventuais diferenças no manejo e adubações realizadas pelos agricultores antes da coleta de solo. O K disponível representou 1-44 \% do $\mathrm{K}$ total do solo, indicando grande variação no comprometimento das reservas de $\mathrm{K}$ do solo e na capacidade de suporte dos solos em manterem a disponibilidade às plantas, no caso de não haver adubações potássicas de manutenção. De qualquer forma, houve correlação significativa entre o K extraído por Mehlich-1 e o K absorvido pelas plantas de arroz (Figura 1b).

$\mathrm{O}$ NaTFB extraiu quantidades semelhantes às do Mehlich-1, exceto para os solos 1 - Gleissolo Melânico, 4 - Planossolo Háplico, 7 - Planossolo Háplico e 2 - Vertissolo Ebânico, nos quais as quantidades extraídas por NaTFB foram superiores (Tabela 2). Nesses casos, além do K "trocável", a quantidade extraída deve ter incluído uma quantidade de $\mathrm{K}$ "não trocável" de liberação rápida, uma vez que a extração ocorreu com apenas uma hora de contato (Moody \& Bell 2006). Esse resultado indica uma provável maior disponibilidade de $\mathrm{K}$ nesses solos, o que pode ser evidenciado pelo maior coeficiente de correlação da extração obtida com o NaTFB e o K absorvido pelas plantas de arroz do que pelo obtido com o extrator Mehlich-1 (Figuras 1b e 1c). Com base nessa observação, é possível considerar que a utilização de um maior período de contato com o NaTFB poderia determinar outras formas de K não trocável (Moody \& Bell 2006), mas também incluir formas de $\mathrm{K}$ de liberação muito lenta às plantas, as quais podem não se tornar disponíveis durante um ou poucos cultivos.

A quantidade absorvida pelas plantas variou de 26,6 $\mathrm{mg} \mathrm{kg}^{-1}$ a 176, $2 \mathrm{mg} \mathrm{kg}^{-1}$ de $\mathrm{K}$, podendo ser considerada uma medida da real disponibilidade de $\mathrm{K}$ dos solos. O método Mehlich-1, usado para diagnóstico da disponibilidade de K para o arroz irrigado no Rio Grande do Sul (CQFS RS/SC 2004, Sosbai 2014), foi capaz de estimar adequadamente a quantidade de $\mathrm{K}$ absorvida pelas plantas (Figuras 1b). Entretanto, quando se utiliza a mesma estratégia empregada no trabalho de Moody \& Bell (2006), é possível verificar que as quantidades de $\mathrm{K}$ absorvidas pelas plantas, em alguns solos, foram maiores do que as variações no K extraído por Mehlich-1 (delta K-Mehlich-1), comportamento que foi evidente para os solos que se posicionaram acima da linha ideal da relação entre essas variáveis (Figura 2). Isso sugere que, nesses solos, houve uma liberação de K de outras formas que não foram estimadas pelo método Mehlich-1, as quais incluem formas não trocáveis.

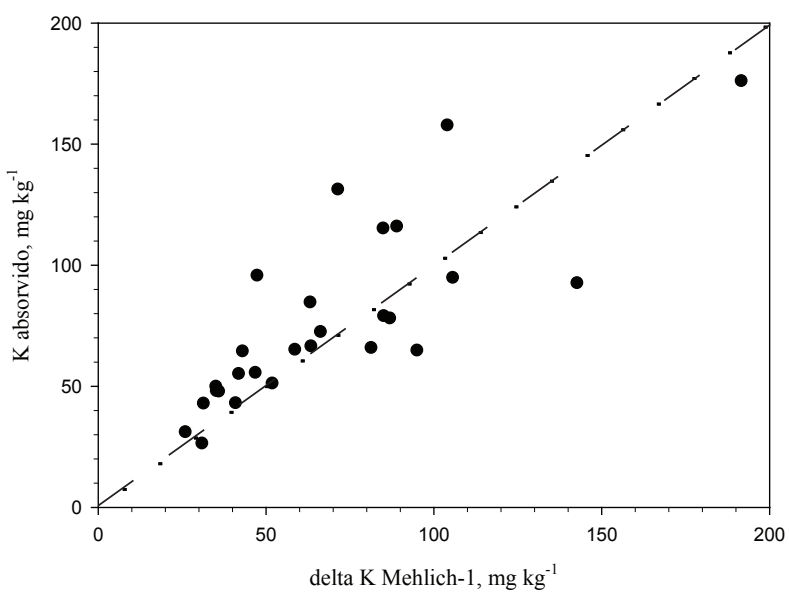

Figura 2. Relação entre o K absorvido pelas plantas de arroz irrigado, cultivadas por 90 dias (acumulado de três cortes da parte área aos 30, 60 e 90 dias de cultivo), e o delta K-Mehlich-1 (diferença entre os valores extraídos do solo antes e após o cultivo das plantas), para 14 solos de várzea do Rio Grande do Sul (Santa Maria, RS, 2015). A linha tracejada representa a relação ideal entre as variáveis e os pontos acima da linha indicam que, nesses solos, houve absorção de K pelas plantas em maior quantidade que a estimada por Mehlich-1. 
Moody \& Bell (2006) observaram que, em média, as plantas absorveram $21 \%$ a mais do $\mathrm{K}$ presente no solo na forma trocável, de maneira semelhante aos resultados de Simonete (1998), que estimou em $29 \%$ a contribuição do K de formas não trocáveis. Acredita-se que seja por essa razão que o K extraído por NaTFB apresentou melhor correlação com o $\mathrm{K}$ absorvido pelas plantas do que o extraído por Mehlich-1 (Figuras 1b e 1c), conforme citado anteriormente.

A evidência de contribuição das formas de $\mathrm{K}$ não estimadas pelo método Mehlich-1, obtidas neste estudo para os diferentes solos, pode ser uma das explicações da falta de resposta da cultura do arroz irrigado às adições desse nutriente via fertilizantes, em alguns tipos de solos (Lopes 1989, Machado \& Franco 1995, Scivittaro \& Machado 2004). Esses resultados também indicam a necessidade de adequação do método a ser utilizado na estimativa da disponibilidade de $\mathrm{K}$ às plantas, para alguns solos de várzea, considerando-se a ampla variação mineralógica e o comportamento desses solos, em relação à disponibilidade de nutrientes. Parte dessa observação já pode ser contemplada com a inclusão de faixas de CTC para interpretação dos valores de $\mathrm{K}$ extraídos por Mehlich-1 e na indicação de doses na cultura do arroz irrigado (Sosbai 2014).

A variação da CTC pode estar associada com as características químicas e mineralógicas. Isso também pode explicar a correlação entre o teor de argila e os valores de $\mathrm{K}$ extraídos por Mehlich-1 $(\mathrm{r}=0,67)$ e NaTFB $(\mathrm{r}=0,75)$ obtida neste trabalho. Entretanto, outros estudos de laboratório, com métodos de extração que envolvam formas mais lábeis de $\mathrm{K}$ não trocável, à semelhança do que foi obtido com o uso do NaTFB, neste trabalho, e de campo, com doses de K, devem ser conduzidos com vistas ao aprimoramento do sistema de recomendação de $\mathrm{K}$ ao arroz irrigado por alagamento.

\section{CONCLUSÕES}

1. Houve ampla variação na quantidade de $\mathrm{K}$ total $\left(138,2-6.733,1 \mathrm{mg} \mathrm{kg}^{-1}\right)$ para a camada superficial $(0-20 \mathrm{~cm})$ dos solos de várzea amostrados.

2. Apesar da correlação significativa, a variação na quantidade de K extraído pelo método Mehlich-1 não explica parte da quantidade de $\mathrm{K}$ absorvido pelas plantas de arroz irrigado, para alguns solos de várzea.
3. O método tetrafenil borato de sódio (NaTFB) com 1 hora de contato, que avalia formas trocáveis e mais lábeis de $\mathrm{K}$ não trocável, foi mais acurado do que o Mehlich-1 para estimar o K disponível em solos de várzea, para a cultura do arroz irrigado por alagamento.

\section{AGRADECIMENTOS}

À Fundação de Amparo à Pesquisa do Estado do Rio Grande do Sul (FAPERGS) e ao Conselho Nacional de Desenvolvimento Científico e Tecnológico (CNPq), pela concessão de bolsas de iniciação científica e de produtividade em pesquisa, e à Coordenação de Aperfeiçoamento de Pessoal de Nível Superior (Capes), pela concessão de bolsa de mestrado e doutorado.

\section{REFERENNCIAS}

BRASIL. Ministério da Agricultura. Departamento Nacional de Pesquisa Agropecuária. Divisão de Pesquisa Pedológica. Levantamento de reconhecimento dos solos do Estado do Rio Grande do Sul. Brasília, DF: Ministério da Agricultura, 1973. (Boletim técnico, 30).

BRITZKE, D. et al. A study of potassium dynamics and mineralogy in soils from subtropical Brazilian lowlands. Journal of Soil and Sediment, Landsberg, v. 12, n. 2, p. 185-197, 2012.

BRITZKE, D. Mineralogia e liberação de potássio em solos de várzea do Rio Grande do Sul. 2010. 76 f. Dissertação (Mestrado em Ciência do Solo) - Universidade Federal de Santa Maria, Santa Maria, 2010.

CASTILHOS, R. M. et al. Mineralogia e fontes de potássio em solos no Rio Grande do Sul cultivados com arroz irrigado. Revista Brasileira de Ciência do Solo, Viçosa, v. 26, n. 3, p. 579-587, 2002.

CASTILHOS, R. M. V.; MEURER, E. J. Suprimento de potássio de solos do Rio Grande do Sul para arroz irrigado por alagamento. Revista Brasileira de Ciência do Solo, Viçosa, v. 26, n. 4, p. 977-982, 2002.

CASTILHOS, R. M. V.; MEURER, E. J.; PINTO, L. F. S. Minerais fontes de potássio em dois Planossolos do RS. In: CONGRESSO BRASILEIRO DE ARROZ IRRIGADO, 1.; REUNIÃO DA CULTURA DO ARROZ IRRIGADO, 22., 1999, Pelotas. Anais... Pelotas: Embrapa Clima Temperado, 1999. p. 330-333.

COMISSÃO DE QUÍMICA E FERTILIDADE DO SOLO - RS/SC (CQFS RS/SC). Manual de adubação e calagem para os Estados do Rio Grande do Sul e Santa Catarina. Porto Alegre: SBCS, 2004. 
COMPANHIA NACIONAL DE ABASTECIMENTO (Conab). Acompanhamento da safra brasileira de grãos: safra 2014/2015: décimo levantamento. Brasília, DF: Conab, 2015.

COX, A. E.; JOERN, B. C.; ROTH, C. B. Non exchangeable ammonium and potassium determination in soils with a modified sodium tetraphenylboron method. Soil Science Society of America Journal, Madison, v. 60, n. 1, p. 114120, 1996.

CURI, N.; KÄMPF, N.; MARQUES, J. J. Mineralogia e formas de potássio em solos brasileiros. In: YAMADA, T.; ROBERTS, T. L. (Eds.). Potássio na agricultura brasileira. Piracicaba: Potafos, 2005. p. 71-91.

DIEL, M. et al. Nutrientes na água para irrigação de arroz na região sul do Rio Grande do Sul, Brasil. Ciência Rural, Santa Maria, v. 37, n. 1, p. 102-109, 2007.

EMPRESA BRASILERIA DE PESQUISA AGROPECUÁRIA (Embrapa). Centro Nacional de Pesquisa de Solos. Sistema brasileiro de classificação de solos. 3. ed. Rio de Janeiro: Embrapa Solos, 2013.

FERREIRA, L. H. G. Substituição parcial de potássio por sódio em arroz (Oryza sativa L.). 2003. 53 f. Dissertação (Mestrado em Agronomia) - Universidade Federal de Pelotas, Pelotas, 2003.

JALALI, M. Kinetics of non-exchangeable potassium release and availability in some calcareous soils of western Iran. Geoderma, Amsterdam, v. 135, n. 1, p. 63-71, 2006.

KÄMPF, N.; CURI, N. Argilominerais em solos brasileiros. In: CURI, N. et al. (Eds.). Tópicos em ciência do solo. Viçosa: Sociedade Brasileira de Ciência do Solo, 2003. p. 1-54.

LOPES, S. I. G. Calibração de análise de solo para arroz irrigado. In: REUNIÃO DA CULTURA DO ARROZ IRRIGADO, 18., Porto Alegre, 1989. Anais... Porto Alegre: Sosbai, 1989. p. 191-195.

MACHADO, M. O. Caracterização e adubação do solo. In: Embrapa-CPATB. Fundamentos para a cultura do arroz irrigado. Campinas: Fundação Cargil, 1985. p. 129-179.

MACHADO, M. O.; FRANCO, J. C. B. Parcelamento da adubação potássica em arroz pré-germinado, no solo de Pelotas (Planossolo). In: REUNIÃO DA CULTURA DO ARROZ IRRIGADO, 21., Porto Alegre, 1995. Anais... Porto Alegre: Sosbai, 1995. p. 177-180.

MALAVOLTA, E. Potassium status of tropical and subtropical region soils. In: MUNSON, R. E. (Ed.). Potassium in agriculture. Madison: American Society of Agronomy, Crop Science Society of America and Soil Science Society of America, 1985. p. 163-200.
MEURER, E. J.; CASTILHOS, R. M. V. Liberação de potássio de frações de solo e sua cinética. Revista Brasileira de Ciência do Solo, Viçosa, v. 25, n. 4, p. 823829, 2001.

MOODY, P. W.; BELL, M. J. Availability of soil potassium and diagnostic soil tests. Australian Journal of Soil Research, Clayton, v. 44, n. 3, p. 265-275, 2006.

NACHTIGALL, G. R.; VAHL, L. C. Dinâmica de liberação de potássio dos solos da região sul do Rio Grande do Sul. Revista Brasileira de Ciência Solo, Viçosa, v. 15, n. 1, p. 43-47, 1991b.

NACHTIGALL, G. R.; VAHL, L. C. Capacidade de suprimento de potássio dos solos da região sul do Rio Grande do Sul. Revista Brasileira de Ciência Solo, Viçosa, v. 15, n. 1, p. 37-42, 1991 a.

PRATT, P. F. Potassium. In: BLACK, C. A. (Ed.). Methods of soil analysis. Madison: American Society of Agronomy, 1973. p. 1022-1032.

PREZOTTI, L. C.; DEFELIPO, B. V. Formas de potássio em solos do Estado de Minas Gerais. Revista Brasileira de Ciência Solo, Viçosa, v. 11, n. 2, p. 109-114, 1987.

RANNO, S. K. Estimativa da disponibilidade de fósforo para a cultura do arroz irrigado em solos do RS. 2004. 139 f. Dissertação (Mestrado em Ciência do Solo) Universidade Federal de Santa Maria, Santa Maria, 2004.

RANNO, S. K. et al. Capacidade de adsorção de fósforo em solos de várzea do Estado do Rio Grande do Sul. Revista Brasileira de Ciência do Solo, Viçosa, v. 31, n. 1, p. 21-28, 2007.

REBERTUS, R. A.; WEED, S. B.; BUOL, S. W. Transformations of biotite to kaolinite during saprolitesoil weathering. Soil Science Society of America Journal, Madison, v. 50, n. 3, p. 810-819, 1986.

SANTOS, H. C. et al. Relações quantidade/intensidade de potássio em solos representativos do Estado da Paraíba Brasil. Revista de Ciências Agrárias, Recife, v. 56, n. 4, p. 338-346, 2013.

SCIVITTARO, W. B.; MACHADO, M. O. Adubação e calagem para a cultura do arroz irrigado. In: GOMES, A. S.; MAGALHÃES JÚNIOR, A. M. (Eds.). Arroz irrigado no Sul do Brasil. Brasília, DF: Embrapa, 2004. p. 259-303.

SHARPLEY, A. N. Relationship between soil potassium forms and mineralogy. Soil Science Society of America Journal, Madison, v. 52, n. 4, p. 1023-1028, 1989.

SIMONETE, M. A. Efeito residual da adubação potássica do azevém sobre o arroz subsequente em plantio direto. 1998. 40 f. Dissertação (Mestrado em Agronomia) Universidade Federal de Pelotas, Pelotas, 1998. 
SOCIEDADE SUL-BRASILEIRA DE ARROZ IRRIGADO (Sosbai). Arroz irrigado: recomendações técnicas da pesquisa para o Sul do Brasil. Porto Alegre: Sosbai, 2014.

SPARKS, D. L. Potassium dynamics in soils. In: STEWART, B. A. (Ed.). Advances in soil sciences. New York: Springer-Verlag, 1987. p. 1-61.

TEDESCO, M. J. et al. Análise de solo, plantas e outros materiais. 2. ed. Porto Alegre: UFRGS, 1995.

TISDALE, S. L. et al. Soil fertility and fertilizers. New York: MacMillan, 1993.
UNAMBA-OPARAH, I. The potassium status of the sandy soils of Northern Imo State, Nigeria. Soil Science Society of America Journal, Madison, v. 139, n. 5, p. 437-445, 1985.

VAHL, L. C. Nutrição de plantas de arroz irrigado. In: PESKE, S. T. et al. Produção de arroz irrigado. 3. ed. Pelotas: Universidade Federal de Pelotas, 2004. p. 153202.

WERLE, R. et al. Lixiviação de potássio em função da textura e da disponibilidade do nutriente no solo. Revista Brasileira de Ciência do Solo, Viçosa, v. 32, n. 6, p. 2297 2305, 2008. 